EGU2020-8358

https://doi.org/10.5194/egusphere-egu2020-8358

EGU General Assembly 2020

(c) Author(s) 2020. This work is distributed under

the Creative Commons Attribution 4.0 License.

\title{
Potential of environmental DNA for tracing land-use based sediment sources
}

Anthony Foucher ${ }^{1}$, Olivier Evrard ${ }^{1}$, G. Francesco Ficetola ${ }^{2,3}$, Ludovic Gielly ${ }^{3}$, Julie Poulain ${ }^{4}$, Charline Giguet-Covex ${ }^{5}$, J. Patrick Laceby ${ }^{6}$, Sébastien Salvador-Blanes ${ }^{7}$, Olivier Cerdan ${ }^{8}$, and Jérôme

Poulenard ${ }^{5}$

'Laboratoire des Sciences du Climat et de l'Environnement (LSCE/IPSL), UMR 8212 (CEA/CNRS/UVSQ) -CEA Saclay - Orme des Merisiers, 91191, Gif-sur-Yvette Cedex, France

${ }^{2}$ Department of Environmental Science and Policy, Università degli Studi di Milano, Milano, Italy

${ }^{3}$ Université Grenoble Alpes, CNRS, Laboratoire d'Écologie Alpine, Grenoble, France

${ }^{4}$ Génomique Métabolique, Genoscope, Institut François Jacob, CEA, CNRS, Univ Evry, Université Paris-Saclay, Evry, France ${ }^{5}$ Université Grenoble Alpes, Université Savoie Mont Blanc, CNRS, EDYTEM (Environnements, DYnamiques et TErritoires de la Montagne), Chambéry, France

${ }^{6}$ Environmental Monitoring and Science Division (EMSD), Alberta Environment and Parks (AEP), Calgary, Alberta, Canada '7aboratoire GéoHydrosystèmes Continentaux (GéHCO), E.A 6293, Université F. Rabelais de Tours, Faculté des Sciences et Techniques, Parc de Grandmont, 37200 Tours, France

${ }^{8}$ Département Risques et Prévention, Bureau de Recherches Géologiques et Minières (BRGM), 3 avenue Claude Guillemin, 45060 Orléans, France

Environmental DNA (eDNA) is a complex mixture of genetic material extracted from environmental samples like soil, water or sediment in order to obtain reliable information on the past and current biological communities. In recent years, the eDNA technique was successfully applied to sediment accumulated in lakes for providing information on past land use and land cover changes in their drainage areas. Recently, the potential of eDNA for providing detailed information on the plant species found in sediment sources was investigated. These research highlight the powerful potential of this method for improving our ability to detect the vegetal communities causing erosion and sediment delivery. Nevertheless, some fundamental questions remain like for example the DNA memory effect of soils. How long the plant signature can persist in soils? Are we recording the last species cultivated or a mixture of past plants in agricultural areas? These issues are of prime importance for examining the potential of eDNA as a new sediment tracer.

To answer these questions, two contrasted sites located in intensively cultivated environments in France were studied. In the first site, soil samples were collected $(n=30)$ in plots for which the crop rotation history was well documented since 1975. In particular, crops cultivated only once during the rotation were used as potential chronological markers. The impact of agricultural practices on eDNA preservation was also investigated comparing soil signatures under conventional and conservation farming. In the second site, samples were collected $(n=40)$ to compare the abundance of currently observed taxa versus detected taxa in cropland, grassland, woodland and river channel banks. 
The results showed that the last cultivated crop was detected in $100 \%$ of the samples as the most abundant taxa under conventional farming and $75 \%$ under no-tillage. The last cultivated species was the most abundant in $80 \%$ of the studied plots. Interestingly, grapevine was detected in $46 \%$ of the cultivated plots of the second site, although this plant is no longer cultivated in this catchment. In addition, a large variety of weeds were detected in both sites in addition to the cultivated species. eDNA results provided by the current research illustrate the potential of this method for identifying the recent ( $<7$ years) land cover history of soils which may allow to improve our understanding of sediment mobilization and transfer processes over short timescales. 